\title{
Assessment of EGNOS Tropospheric Correction Model
}

\author{
Nigel Penna, Alan Dodson and Wu Chen \\ (IESSG, University of Nottingham)
}

\begin{abstract}
Within the implementation of the European Geo-stationary Navigation Overlay System (EGNOS), a significant residual error in positioning is due to tropospheric delay effects. The EGNOS guidelines recommend that tropospheric delay is modelled using an empirical correction algorithm based on a receiver's height and estimates of meteorological parameters developed from average and seasonal variation data. However, such a simple average and seasonal variation model is unlikely to emulate temporal weather changes exactly. The potential errors involved in the application of the recommended algorithm and the consequent effects on the positioning errors, under typical UK weather conditions, are detailed in this paper. This was achieved by comparing tropospheric delays produced by the EGNOS model, with tropospheric delays estimated from high precision carrier phase GPS, over a one-year period for five UK stations. The RMS EGNOS model zenith tropospheric delay errors ranged from 4.0 to $4.7 \mathrm{~cm}$, with maximum errors ranging from 13.2 to $17 \cdot 8 \mathrm{~cm}$. The errors were also shown to be spatially correlated. The subsequent effect on position error is shown to be dependent on the satellite elevation cut-off angle adopted and on whether or not the observations are weighted according to the satellite elevation angle.
\end{abstract}

\section{KEY WORDS \\ 1. GNSS. 2. Augmentation. 3. Trials.}

1. INTRODUCTION. Tropospheric delay is one of the major error sources in satellite navigation. The signal transmission delay caused by the troposphere can be over $2 \mathrm{~m}$ at the zenith and $20 \mathrm{~m}$ at lower receiver-to-satellite elevation angles such as below 10 degrees. Incorrect mitigation of the tropospheric delay can result in positioning errors of $10 \mathrm{~m}$ or greater.

The European Geo-stationary Navigation Overlay System (EGNOS) is the European initiative for the implementation of the Global Navigation Satellite System-1 (GNSS-1). It comprises a number of ground Receiver Integrity Monitors (RIMs) and geo-stationary satellites. The RIMS provide the integrity and Wide Area Differential GPS (WADGPS) services for both the USA's Global Positioning System (GPS) and Russia's Global'naya Navigatsionnaya Sputnikovaya Sistema (GLONASS). The geo-stationary satellites are used to broadcast the integrity and WADGPS corrections to the users, but also provide extra pseudo-range observations in addition to those from GPS and GLONASS. The WADGPS service separates the measurement errors into different components, namely orbit, satellite clock, ionospheric delay and tropospheric delay, to enable these corrections to be applied over a wide area. However, due to the large variation in tropospheric delay with 
different weather conditions that may prevail across the wide area considered, the tropospheric delay correction is not broadcast to the user. Instead an estimate is generated locally by the user, based on a tropospheric model.

The EGNOS guidelines recommend that a user applies a correction for tropospheric delay that is compliant with the International Civil Aviation Organisation (ICAO) Standards and Recommended Practices (SARPs) for SatelliteBased Augmentation Systems (SBAS) (RTCA, 1999). In addition to EGNOS, these guidelines also cover the USA Wide Area Augmentation System (WAAS) and the Japanese Multi-functional Transport Satellite, MTSAT-based Satellite Augmentation System (MSAS). The recommended SBAS model (hereafter termed simply the EGNOS model in this paper), provides an estimate of the zenith total tropospheric delay that is dependent on empirical estimates of five meteorological parameters at a receiver - namely, pressure, temperature, water vapour pressure, temperature lapse rate and water vapour lapse rate. These estimates of the meteorological parameters are dependent on the receiver's height, latitude and day-of-year, and are interpolated from reference values for the yearly averages of the parameters and their associated seasonal variations, derived primarily from North American meteorological data. This is so that the EGNOS model is consistent with the tropospheric model for the WAAS program detailed in Collins and Langley (1997) and also discussed in Collins and Langley (1998). The EGNOS guidelines then recommend mapping the zenith total tropospheric delay estimate to the appropriate receiver-to-satellite elevation angle using an elevation angle, dependent mapping function.

It is not possible for a simple empirical model, such as the EGNOS model, to emulate tropospheric delay variations exactly, especially outside the area from which data were gathered to derive the meteorological parameter values used by the model. To assess the performance of the EGNOS tropospheric model, data was analysed from five different locations covering the spatial extent of the UK over a period of one year to account for seasonal weather variations. This extends the work detailed by Dodson et al. (1999b), in which the error in the tropospheric delay due to the use of the EGNOS model was assessed by comparison with GPS carrier phase derived estimates, and the subsequent position errors analysed, for two UK locations, over one week samples from winter, spring, summer and autumn.

Zenith total tropospheric delays were estimated every 15 minutes for five UK GPS stations over a period of one year using carrier phase GPS measurements. By comparison with radiosonde measurements, the zenith tropospheric delays were shown to be correct to about $1 \mathrm{~cm}$. For each station, these zenith total tropospheric delays were used as 'truth' values with which to compare the EGNOS model derived zenith total tropospheric delays. Not only did this enable the validity of the EGNOS model to be assessed at different locations, but also its performance was studied over both seasonal and short period time scales. The latter included periods when tropospheric conditions changed very rapidly with time, such as a few hours or less. GPS data were then simulated with the 'truth' tropospheric delay values (that were estimated using the carrier phase GPS data) applied in the data simulation. The simulated data were input to a least squares position estimation program, and the resultant position errors due to the application of the EGNOS tropospheric delay model were obtained.

The EGNOS tropospheric correction model is firstly described in section 2, with the comparison of the zenith total tropospheric delays from the EGNOS model and 
the 'truth' values obtained using carrier phase GPS data, detailed in section 3. The resultant position errors due to the implementation of the EGNOS model are described in section 4, with conclusions detailed in section 5 .

2. EGNOS TROPOSPHERIC CORRECTION MODEL. The EGNOS guidelines (RTCA, 1999) recommend users to model the total tropospheric delay for a receiver-to-satellite range at elevation angle $\alpha$ using:

$$
d_{\alpha}=\left(d_{d r y}+d_{w e t}\right) \times M F(\alpha),
$$

where: $d_{d r y}$ is the zenith 'dry' (hydrostatic) delay

$d_{\text {wet }}$ is the zenith 'wet' delay

$M F(\alpha)$ is the mapping function to 'map' the zenith total delay to the appropriate receiver-to-satellite elevation angle.

The EGNOS model provides an estimate of the zenith total tropospheric delay that is dependent on five meteorological parameters, obtained from a look-up table of values given at discrete latitudes, with linear interpolation applied as necessary. Attempts to model the seasonal variation of the parameters is via a sinusoidal function of the day-of-year. The five meteorological parameters are the total pressure, temperature and water vapour pressure at mean sea level, and temperature and water vapour lapse rates, used to scale the pressures and temperatures to the user's height above sea level (Collins and Langley, 1998). Hence the zenith 'dry' and 'wet' delays are computed using:

$$
\begin{aligned}
& d_{d r y}=z_{d r y}\left[1-\frac{\beta H}{T}\right]^{\frac{g}{R_{d d^{\beta}}}} \text { and } \\
& d_{\text {wet }}=z_{\text {wet }}\left[1-\frac{\beta H}{T}\right]^{\frac{(1+1) g}{R_{d d^{\beta}}}-1},
\end{aligned}
$$

where: $g=9 \cdot 80665 \mathrm{~m} / \mathrm{s}^{2}$

$H$ is the height of the receiver above mean sea level (m),

$T$ is the temperature at mean sea level $(\mathrm{K})$,

$\beta$ is the temperature lapse rate $(\mathrm{K} / \mathrm{m})$,

$R_{d}=287.054 \mathrm{~J} / \mathrm{kg} / \mathrm{K}$,

$\lambda$ is the water vapour lapse rate (dimensionless),

$z_{d r y}$ is the zenith 'dry' delay at mean sea level,

$z_{\text {wet }}$ is the zenith 'wet' delay at mean sea level.

Now

$$
z_{d r y}=\frac{10^{-6} k_{1} R_{d} P}{g_{m}}
$$

where: $k_{1}=77.604 \mathrm{~K} / \mathrm{mbar}$,

$P$ is the pressure at mean sea level (mbar),

and $g_{m}=9.784 \mathrm{~m} / \mathrm{s}^{2}$,

$$
z_{w e t}=\frac{10^{-6} k_{2} R_{d}}{g_{m}(\lambda+1)-\beta R_{d}} \times \frac{e}{T},
$$

where: $k_{2}=382000 \mathrm{~K}^{2} / \mathrm{mbar}$,

$e$ is the water vapour pressure at mean sea level (mbar). 
The average values and seasonal variations for the five meteorological parameters are given in Table 1.

Table 1. Average values and seasonal variation values of the five meteorological parameters used by the EGNOS model.

\begin{tabular}{|c|c|c|c|c|c|}
\hline \multicolumn{6}{|c|}{ Average } \\
\hline Latitude $\left(^{\circ}\right)$ & $P_{0}(\mathrm{mbar})$ & $T_{0}(\mathrm{~K})$ & $e_{0}(\mathrm{mbar})$ & $\beta_{0}(\mathrm{~K} / \mathrm{m})$ & $\lambda_{0}$ \\
\hline$\leqslant 15$ & $1013 \cdot 25$ & $299 \cdot 65$ & $26 \cdot 31$ & $6 \cdot 30 \mathrm{e}-3$ & $2 \cdot 77$ \\
\hline 30 & $1017 \cdot 25$ & $294 \cdot 15$ & $21 \cdot 79$ & $6 \cdot 05 e-3$ & $3 \cdot 15$ \\
\hline 45 & $1015 \cdot 75$ & $283 \cdot 15$ & $11 \cdot 66$ & $5 \cdot 58 \mathrm{e}-3$ & $2 \cdot 57$ \\
\hline 60 & $1011 \cdot 75$ & $272 \cdot 15$ & $6 \cdot 78$ & $5 \cdot 39 e-3$ & $1 \cdot 81$ \\
\hline$\geqslant 75$ & $1013 \cdot 00$ & $263 \cdot 65$ & $4 \cdot 11$ & $4 \cdot 53 e-3$ & 1.55 \\
\hline \multicolumn{6}{|c|}{ Seasonal Variation } \\
\hline Latitude $\left(^{\circ}\right)$ & $\Delta P$ (mbar) & $\Delta T(\mathrm{~K})$ & $\Delta e$ (mbar) & $\Delta \beta(\mathrm{K} / \mathrm{m})$ & $\Delta \lambda$ \\
\hline$\leqslant 15$ & $0 \cdot 00$ & $0 \cdot 00$ & $0 \cdot 00$ & $0 \cdot 00 \mathrm{e}-3$ & $0 \cdot 00$ \\
\hline 30 & $-3 \cdot 75$ & $7 \cdot 00$ & $8 \cdot 85$ & $0 \cdot 25 \mathrm{e}-3$ & $0 \cdot 33$ \\
\hline 45 & $-2 \cdot 25$ & $11 \cdot 00$ & $7 \cdot 24$ & $0 \cdot 32 \mathrm{e}-3$ & $0 \cdot 46$ \\
\hline 60 & -1.75 & $15 \cdot 00$ & $5 \cdot 36$ & $0 \cdot 81 \mathrm{e}-3$ & 0.74 \\
\hline$\geqslant 75$ & $-0 \cdot 50$ & $14 \cdot 50$ & $3 \cdot 39$ & $0 \cdot 62 \mathrm{e}-3$ & $0 \cdot 30$ \\
\hline
\end{tabular}

Using the values detailed in Table 1, each meteorological parameter value $(\xi)$ may then be computed using:

$$
\xi(\phi, D)=\xi_{0}(\phi)-\Delta \xi(\phi) \times \cos \left[\frac{2 \pi\left(D-D_{\min }\right)}{365 \cdot 25}\right],
$$

where: $\phi$ is the receiver's latitude,

$D$ is the day-of-year (starting with 1 January),

$D_{\min }=28$ for northern latitudes,

$D_{\text {min }}=211$ for southern latitudes,

$\xi_{0}$ and $\Delta \xi$ are the average and seasonal variation respectively for the particular parameter at the receiver's latitude.

The mapping function $(M F(\alpha))$ is expressed as:

$$
M F(\alpha)=\frac{1 \cdot 001}{\sqrt{0 \cdot 002001+\sin ^{2} \alpha}} .
$$

The mapping function is not valid for elevation angles of less than 5 degrees (RTCA, 1999).

3. EVALUATION OF ZENITH TOTAL TROPOSPHERIC DELAYS FROM THE EGNOS MODEL. Weather effects, and consequently tropospheric delay, are highly variable both temporally and spatially. To model rapid variations in tropospheric delay, meteorological measurements are needed at a frequency that matches any variation in the behaviour of the troposphere. Since the EGNOS empirical model is essentially a seasonal model that does not attempt to model sub-seasonal variations, it is unlikely that the EGNOS tropospheric model 


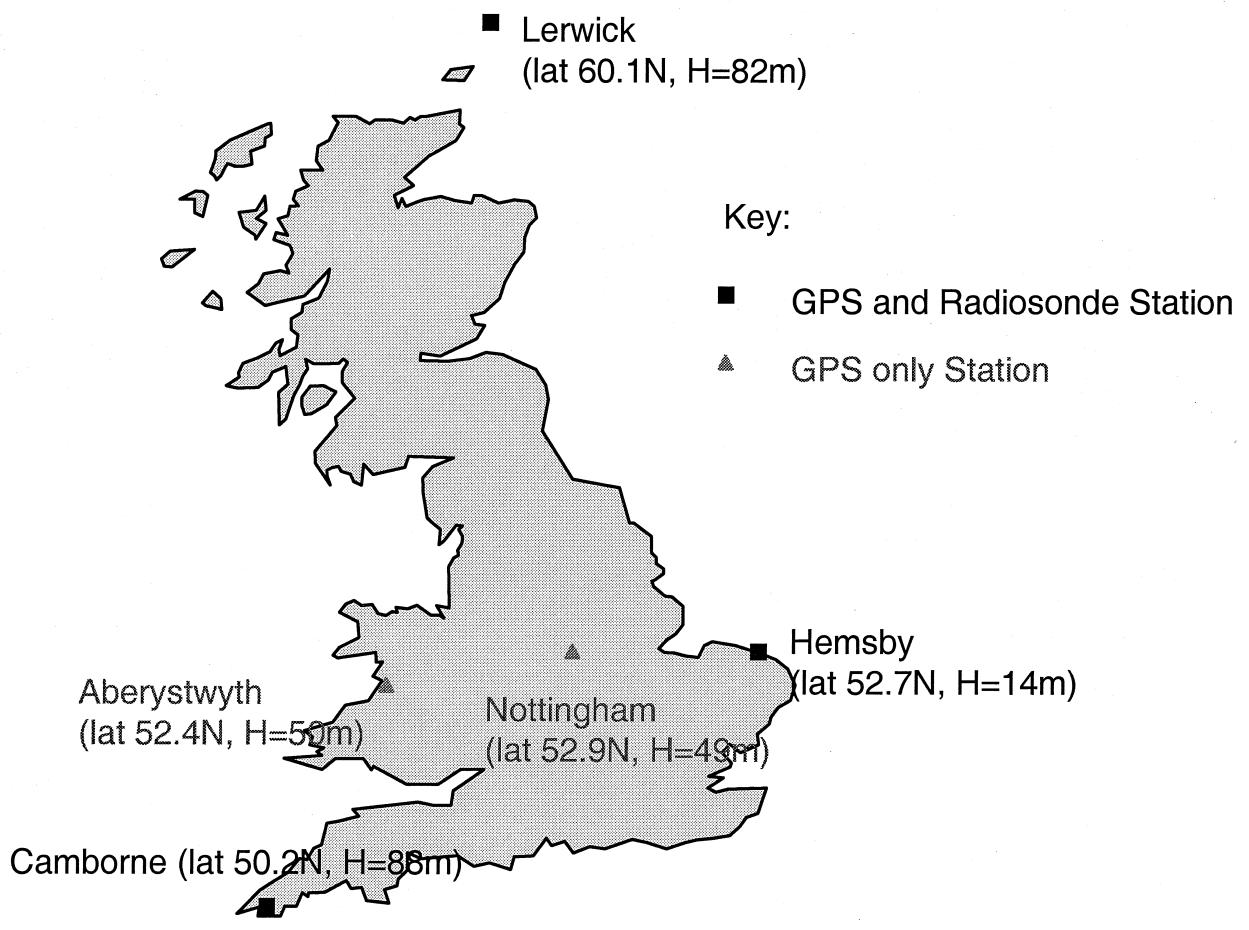

Figure 1. Stations at which the EGNOS model was compared with GPS estimates (latitudes are degrees, with heights above mean sea level $(\mathrm{H})$ also shown).

alone will fully mitigate tropospheric delay effects. Consequently, to assess the suitability of the application of the EGNOS tropospheric model when seasonal and sub-seasonal variations in tropospheric behaviour arise, zenith total tropospheric delay values from the EGNOS model were compared with those obtained from the analysis of one year of GPS carrier phase data.

GPS data collected from April 1998 to March 1999 at five stations of the UK Permanent GPS Network (Dodson et al., 1999a) were routinely processed to produce zenith total tropospheric delay estimates as piecewise constant parameters every 15 minutes. These estimates were obtained using the GPS data and processing software alone; thus no external meteorological data were used to estimate the tropospheric delay. Stations were selected to provide as great a range of latitude across the UK as possible, and ideally at radiosonde launch sites, where ground-based pressure and temperature measurements were also being taken. Since the pressure data, together with the station's latitude and height above sea level, could be used to compute the zenith hydrostatic delay (Saastamoinen, 1972), the zenith wet delay could be obtained by simple subtraction from the estimated zenith total delay. Using the temperature data, the zenith wet delay could be converted to integrated precipitable water vapour (Bevis et al., 1992) and compared with the integrated precipitable water vapour obtained from the radiosondes, thus providing external control on the GPS estimates of tropospheric delays. The stations selected were Camborne (CAMB), Aberystwyth (ABYW), Hemsby (HEMS), Nottingham (NOTT) and Lerwick (LERW), as shown in Figure 1. 


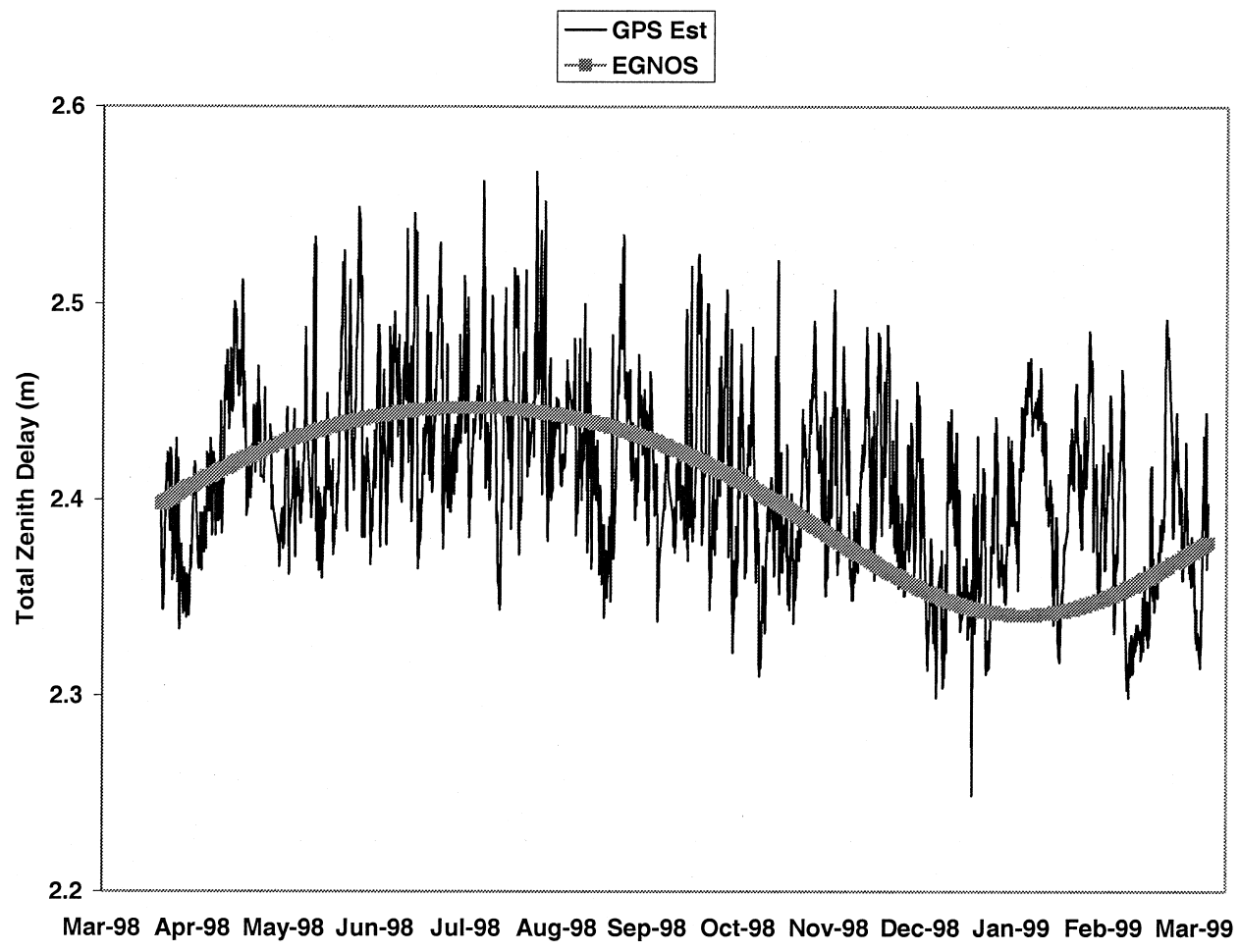

Figure 2. GPS and EGNOS model estimates for zenith total tropospheric delay at Camborne.

3.1. GPS 'Truth' Zenith Total Tropospheric Delays. The GPS data from the five stations were processed routinely for each day in a double difference network using GPS Analysis Software (GAS) developed in-house. The processing strategy adopted for each routine daily GPS network solution was the fixing of previously welldetermined ITRF94 coordinates for each station, together with the fixing of the final International GPS Service (IGS) ephemeris (IGS, 2000) to provide the satellite coordinates and clock offsets. The final IGS precise ephemeris is said to be accurate to about $5 \mathrm{~cm}$ (IGS, 2000), hence when used in double differencing processing software, orbital errors were assumed to be negligible. The dual frequency carrier phase GPS data were combined linearly to eliminate first-order ionospheric delay effects, together with systematic error models applied to correct for the effects of Earth body tides (McCarthy, 1992), antenna phase centre variations (Rothacher and Mader, 1996) and ocean tide loading constituents M2, S2, N2, K2, K1, O1, P1, Q1, Mf and Mm (Baker et al., 1995), generated using the Le Provost et al. (1994) model and applied according to McCarthy (1996). All double difference observations were assigned equal weights, adopting a 15 degrees elevation angle cut-off and a 180 seconds processing interval, with the ambiguities not integer fixed. The zenith total tropospheric delay was estimated per station as piecewise constant parameters every 15 minutes using a random walk Kalman filter approach (Dodson et al., 1996), with a process noise of $0.4 \mathrm{~mm} / \sqrt{\mathrm{hr}}$ used to constrain adjacent estimates. The Niell mapping function (Niell, 1996) was used to map the zenith total delay to the appropriate receiver-to-satellite elevation angle. 
Table 2. Precision of GPS integrated precipitable water vapour (ipwv) estimates over one year.

\begin{tabular}{lcc}
\hline Station & $\begin{array}{c}\text { Number of Common } \\
\text { Epochs }\end{array}$ & $\begin{array}{c}\text { IPWV Standard Deviation } \\
\text { Between GPS and Radiosonde } \\
\text { Estimates (mm) }\end{array}$ \\
\hline Camborne & 1038 & 1.65 \\
Hemsby & 1113 & 1.34 \\
Lerwick & 1143 & 1.61 \\
\hline
\end{tabular}

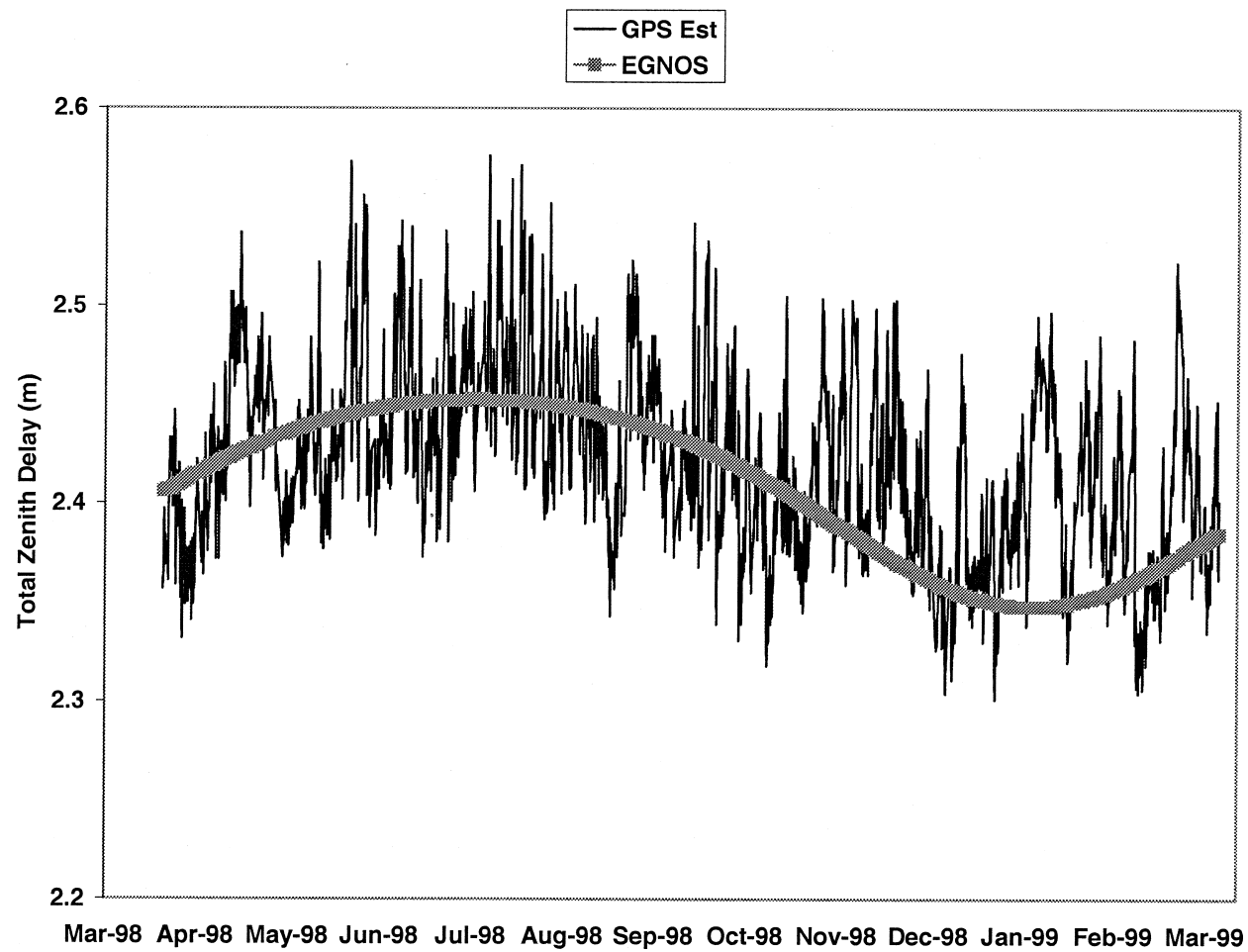

Figure 3. GPS and EGNOS model estimates for zenith total tropospheric delay at Aberystwyth.

Radiosonde-derived integrated precipitable water vapour (every 6 or 12 hours), plus ground-based pressure and temperature data were available for Camborne, Hemsby and Lerwick. Thus, GPS-derived integrated precipitable water vapour estimates were obtained and compared with the radiosonde estimates at these three stations, enabling a quality assessment of the GPS tropospheric delay estimates to be obtained. Hence the standard deviations, over the one-year period, for the integrated precipitable water vapour time series derived from GPS from those derived from radiosondes were computed and are shown in Table 2.

It can be seen from Table 2 that, by comparison with radiosonde data, the integrated precipitable water vapour estimates obtained from GPS over the one-year 
period are correct to about $1.5 \mathrm{~mm}$. If for example, a mean surface temperature value of $10^{\circ} \mathrm{C}$ is adopted, based on Bevis et al. (1992), an integrated precipitable water vapour to wet delay conversion factor of 6.4 is obtained. This indicates that the precision of the zenith total tropospheric delays estimated over the course of one year from GPS is approximately $1 \mathrm{~cm}$.

3.2. Comparison of EGNOS Model and GPS 'Truth' Zenith Total Tropospheric Delays. The zenith total tropospheric delays for each of the five UK stations considered were computed using the EGNOS model for each of the epochs when a GPS-derived estimate of zenith total tropospheric delay was available. For each station, these two data time series from 19 April 1998 to 29 March 1999 are plotted in Figures 2-6.

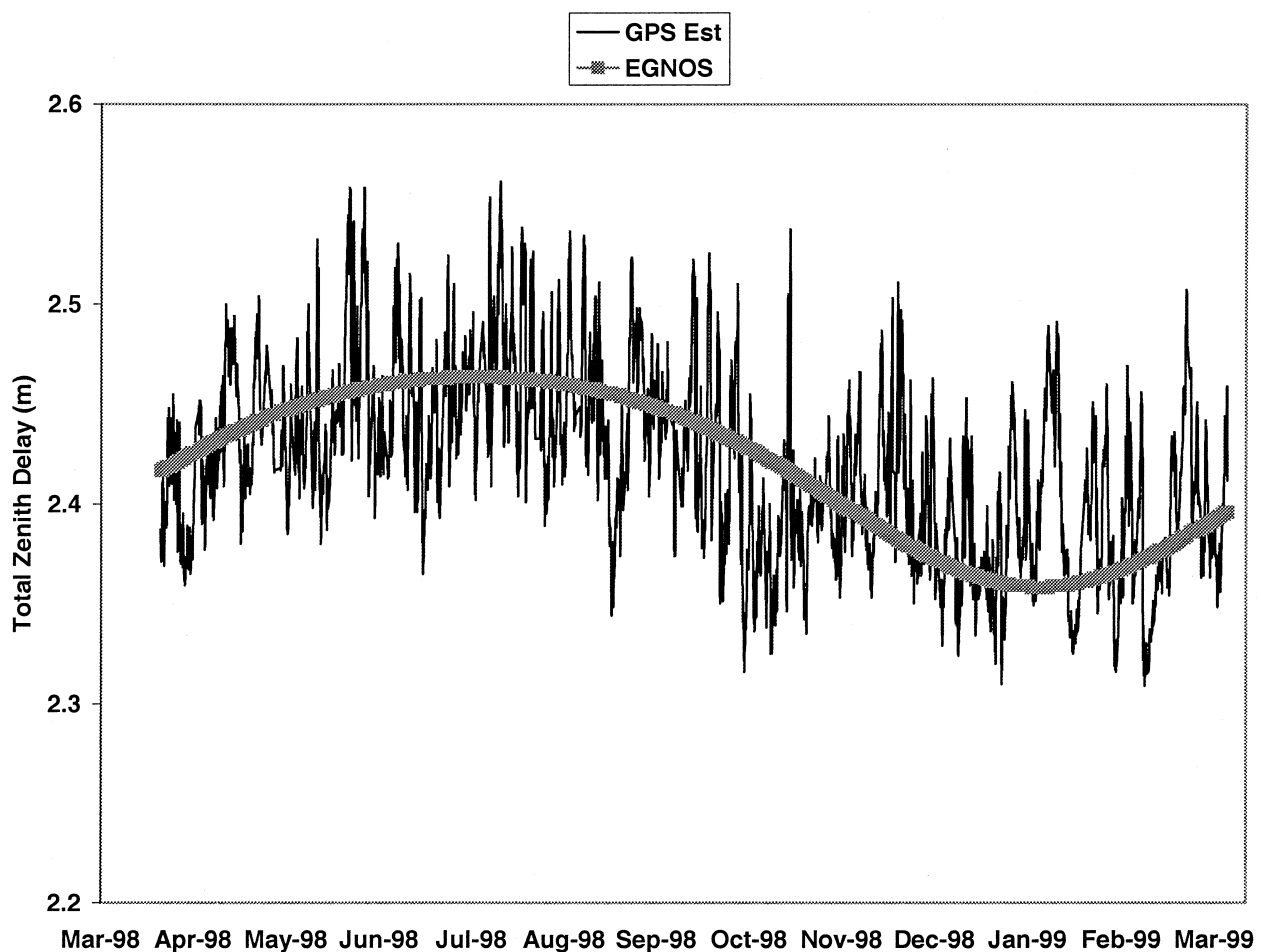

Figure 4. GPS and EGNOS model estimates for zenith total tropospheric delay at Hemsby.

It can be seen from visual inspection of Figures $2-6$ that, for all five stations, the EGNOS model agrees with the average seasonal trends of the GPS estimates extremely well. To quantify the agreement, the RMS of the differences between the EGNOS model and the GPS estimates over the one-year period for each of the five stations were computed and are listed in Table 3. Also shown in Table 3 are the maximum differences arising over the period at each of the five stations.

From Table 3, it can be seen that the RMS differences between the EGNOS model and the GPS estimates for each of the five stations range from $4 \cdot 0 \mathrm{~cm}$ to $4.7 \mathrm{~cm}$. 


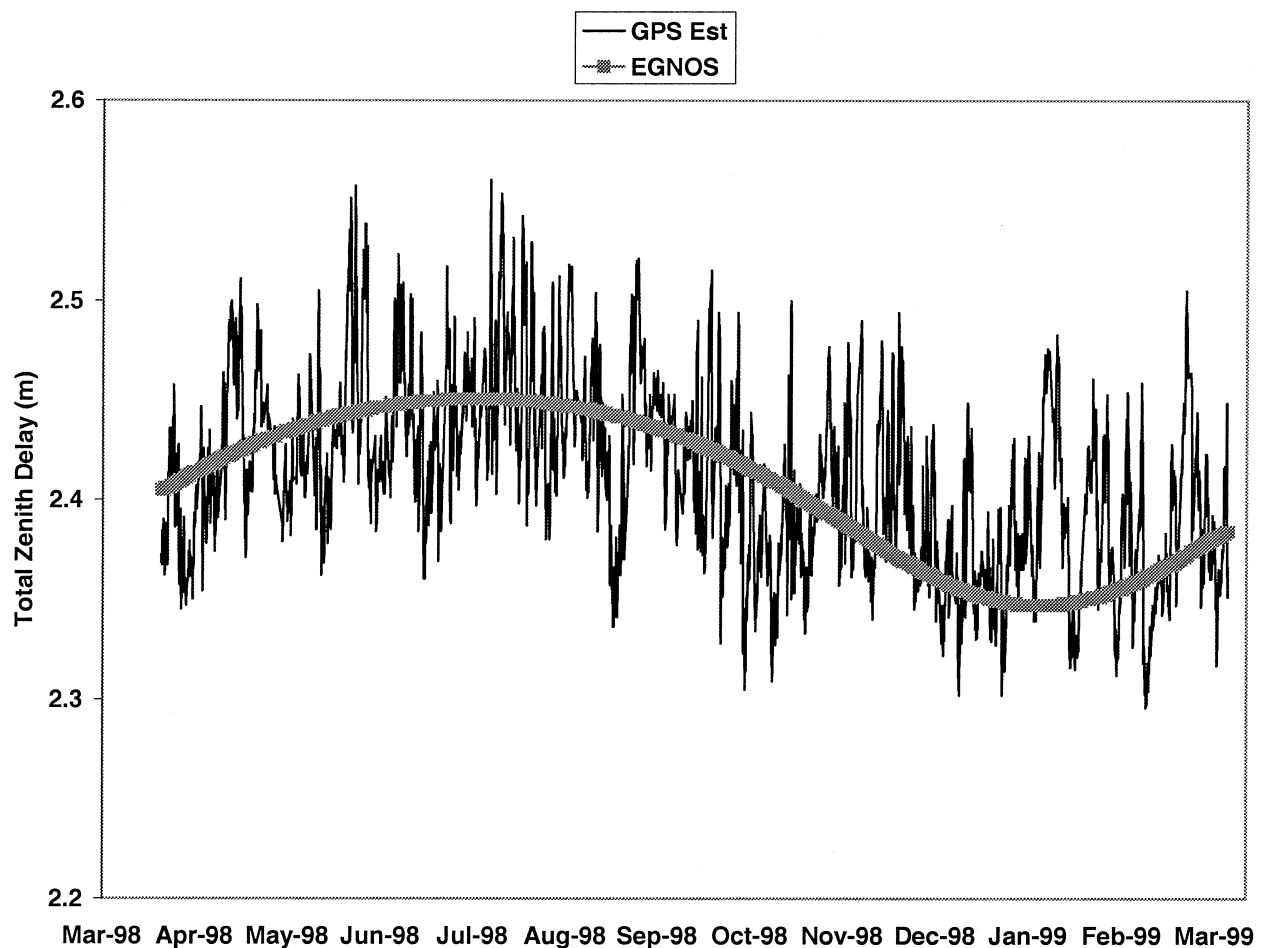

Figure 5. GPS and EGNOS model estimates for zenith total tropospheric delay at Nottingham.

These statistics include periods when there are clearly short-term weather variations (over time periods of hours and days) when, as expected, the simple latitude, height and day-of-year dependent empirical EGNOS model does not agree with the GPS estimates very well. The largest maximum difference is $17.8 \mathrm{~cm}$, for Lerwick on 30 January 1999, and the smallest maximum difference is $13.2 \mathrm{~cm}$, for Hemsby, on 3 February 1999. However, from Table 3, it can be deduced that for all five stations, between 72 and $78 \%$ of these differences are less than $5 \mathrm{~cm}$, and between 96 and $99 \%$ of the differences less than $10 \mathrm{~cm}$. In addition, at all but one of the five stations (Aberystwyth), the percentage of epochs for which the zenith delay error exceeds $12.0 \mathrm{~cm}$ is less than $1 \%$. This is highlighted since the EGNOS guidelines (RTCA, 1999) stipulate that the user is required to apply a correction for tropospheric delay based on a model with residual error less than $12 \cdot 0 \mathrm{~cm}$.

3.3. Correlation of EGNOS Model Errors across the UK. If Figures 2-6 are inspected closely, it is apparent that there are times when not only are there significant differences (errors) between the EGNOS model and the GPS estimates, but that these errors are of the same nature at several of the five UK stations, for example in April/May 1998 and January 1999. Consequently, for all the EGNOS model error estimates obtained per station every 15 minutes over the one-year period, the linear correlation coefficients for each pair of stations were computed and are listed in Table 4, together with the inter-station distances. In addition, to smooth the effect of 


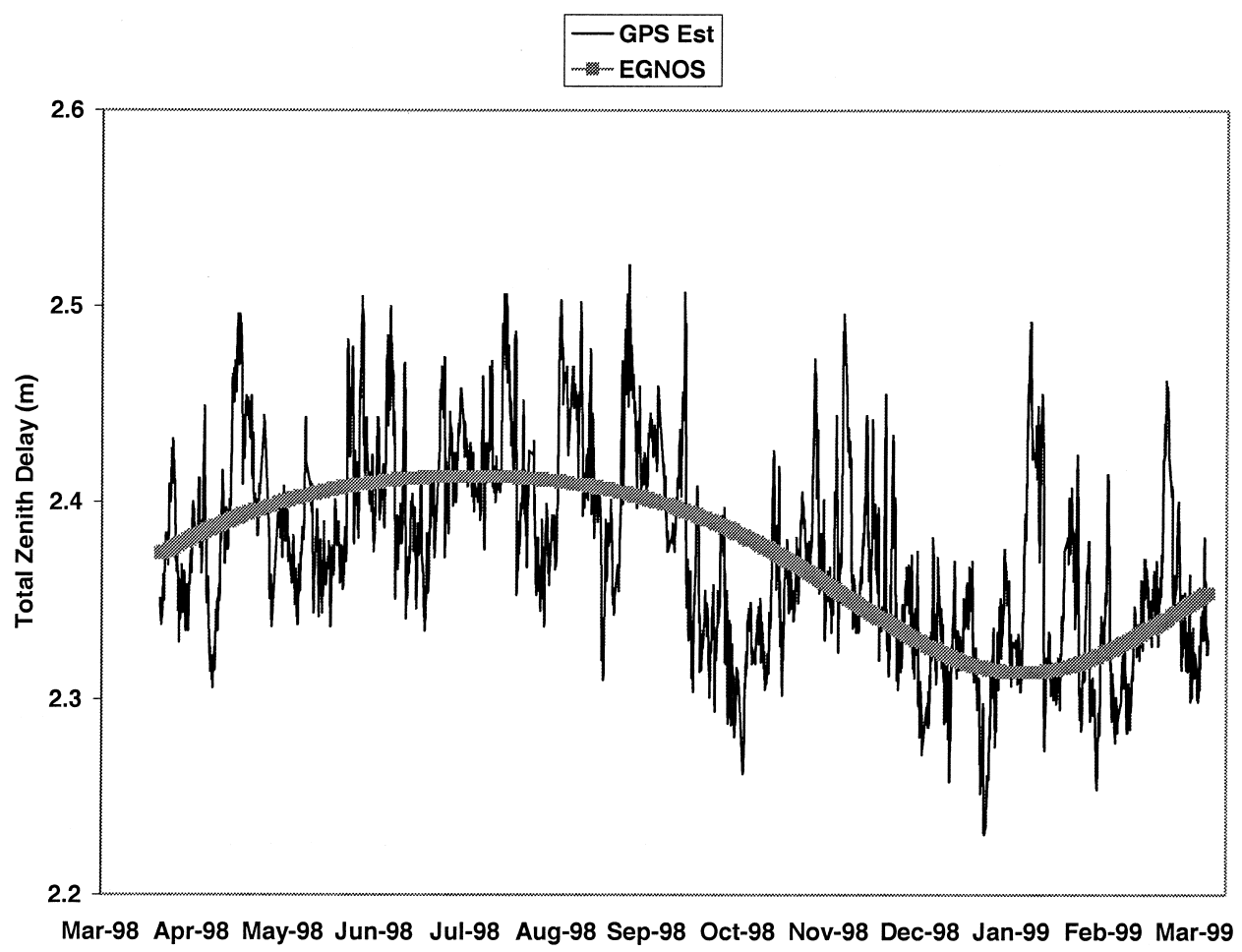

Figure 6. GPS and EGNOS model estimates for zenith total tropospheric delay at Lerwick.

Table 3. EGNOS model zenith total tropospheric delay RMS errors compared with GPS estimated zenith total tropospheric delays every 15 minutes.

\begin{tabular}{|c|c|c|c|c|c|c|c|c|}
\hline \multirow[b]{2}{*}{ Station } & \multirow{2}{*}{$\begin{array}{l}\text { Lat } \\
\left({ }^{\circ}\right)\end{array}$} & \multirow{2}{*}{$\begin{array}{c}\mathrm{H} \\
(\mathrm{m})\end{array}$} & \multirow{2}{*}{$\begin{array}{c}\text { RMS } \\
\text { Error } \\
(\mathrm{cm})\end{array}$} & \multirow{2}{*}{$\begin{array}{l}\text { Max } \\
\text { Error } \\
(\mathrm{cm})\end{array}$} & \multicolumn{4}{|c|}{ \% Epochs with Error Exceeding: } \\
\hline & & & & & $5 \mathrm{~cm}$ & $10 \mathrm{~cm}$ & $12 \mathrm{~cm}$ & $15 \mathrm{~cm}$ \\
\hline CAMB & $50 \cdot 2 \mathrm{~N}$ & 88 & $4 \cdot 66$ & 13.9 & $28 \cdot 0$ & $3 \cdot 8$ & 0.7 & $0 \cdot 0$ \\
\hline $\mathrm{ABYW}$ & $52 \cdot 4 \mathrm{~N}$ & 50 & $4 \cdot 57$ & $14 \cdot 9$ & $26 \cdot 1$ & $3 \cdot 9$ & $1 \cdot 1$ & $0 \cdot 0$ \\
\hline HEMS & $52 \cdot 7 \mathrm{~N}$ & 14 & 3.99 & $13 \cdot 2$ & $21 \cdot 1$ & $1 \cdot 3$ & $0 \cdot 3$ & $0 \cdot 0$ \\
\hline NOTT & $52 \cdot 9 \mathrm{~N}$ & 49 & $4 \cdot 15$ & $13 \cdot 6$ & $23 \cdot 0$ & $1 \cdot 8$ & $0 \cdot 4$ & $0 \cdot 0$ \\
\hline LERW & $60 \cdot 1 \mathrm{~N}$ & 82 & $4 \cdot 20$ & $17 \cdot 8$ & $21 \cdot 9$ & $2 \cdot 0$ & $0 \cdot 9$ & $0 \cdot 2$ \\
\hline
\end{tabular}

model errors due to short-term, localised weather variations, daily averages of the EGNOS model errors per station and the associated linear correlation coefficients for each pair of stations were computed. These are also listed in Table 4.

The variations with inter-station distance of the EGNOS model correlation coefficients listed in Table 4 are shown graphically in Figure 7.

It can be seen from the correlation coefficients listed in Table 4 and plotted in Figure 7 that the degree of linear correlation between the EGNOS model errors at a pair of stations is dependent on the distance between the stations. It can also be seen that there is almost perfect inverse linear correlation between the EGNOS model error correlations for a station pair and the inter-station distance. Furthermore, the 
Table 4. Correlation of EGNOS model errors between station pairs.

\begin{tabular}{lccc}
\hline & $\begin{array}{c}\text { Inter-Station Distance } \\
(\mathrm{km})\end{array}$ & \multicolumn{2}{c}{ Correlation Coefficient of EGNOS Model Errors } \\
\cline { 3 - 4 } Station Pair & 196 & 15 min Errors & Daily Average of Errors \\
\hline HEMS-NOTT & 198 & $0 \cdot 81$ & $0 \cdot 91$ \\
ABYW-NOTT & 262 & $0 \cdot 85$ & $0 \cdot 92$ \\
ABYW-CAMB & 387 & $0 \cdot 81$ & $0 \cdot 88$ \\
ABYW-HEMS & 417 & $0 \cdot 65$ & $0 \cdot 79$ \\
CAMB-NOTT & 801 & $0 \cdot 69$ & $0 \cdot 77$ \\
LERW-NOTT & 850 & $0 \cdot 53$ & $0 \cdot 63$ \\
HEMS-LERW & 876 & $0 \cdot 50$ & $0 \cdot 57$ \\
ABYW-LERW & 1133 & $0 \cdot 33$ & $0 \cdot 58$ \\
CAMB-LERW & & & $0 \cdot 40$ \\
\hline
\end{tabular}

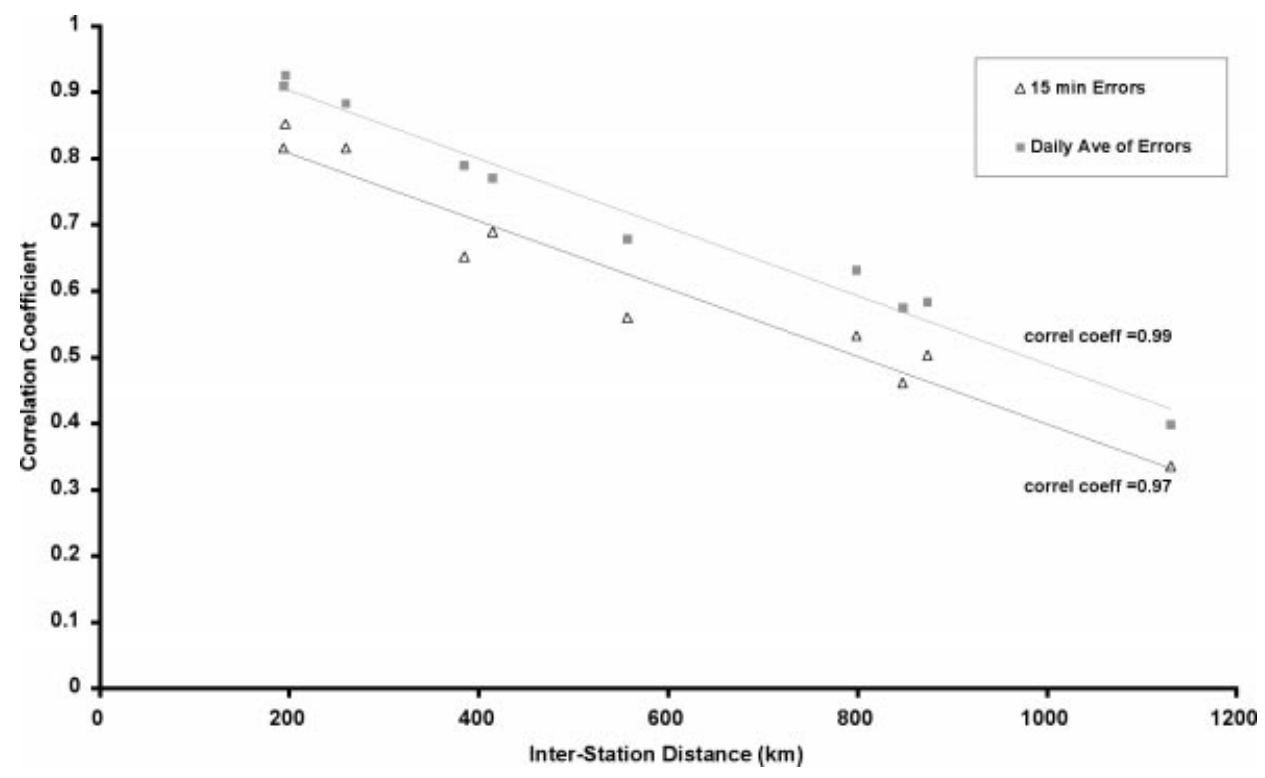

Figure 7. Correlation of EGNOS model errors between station pairs.

magnitudes of the correlations are significant, for even with station separations of $1000 \mathrm{~km}$ the linear correlation coefficient is about $0 \cdot 5$, whilst for station separations of about $200 \mathrm{~km}$ the linear correlation coefficients are about 0.9 for the daily averaged error case. Even when no daily averaging of the EGNOS model errors has been carried out, the linear correlation of the errors is still about 0.8 for station separations of about $200 \mathrm{~km}$. This implies that considerable reductions in the tropospheric delay error could be obtained by augmenting the EGNOS model with corrections broadcast to the user from reference stations up to $1000 \mathrm{~km}$ distant, at which continuous estimation of the tropospheric delay, using high precision carrier phase GPS, could be realised. 
4. EVALUATION OF THE EGNOS MODEL MAPPING FUNCTION. The EGNOS model's mapping function was compared with the Niell mapping function (Niell, 1996). The Niell mapping function was used in the computation of the 'truth' GPS estimated tropospheric delays described in section 3, and is a geodetically precise mapping function. However, unlike the EGNOS model's mapping function, which is dependent only on the receiver-to-satellite elevation angle, the Niell mapping function is more complicated and depends on latitude, station height, and day-of-year. Using the approach detailed by Dodson et al. (1999b), for elevation angles of 20 degrees and less, the values of both the EGNOS and Niell mapping functions were computed and compared for 30 January 1999 for Lerwick. These differences are given in Table 5.

Table 5. Differences between the EGNOS and Niell mapping functions at low elevation angles for Lerwick on 30 January 1999.

\begin{tabular}{lccccc}
\hline Elevation Angle $\left(^{\circ}\right)$ & 1 & 5 & 10 & 15 & 20 \\
\hline Difference & $3 \cdot 8$ & $0 \cdot 08$ & $0 \cdot 03$ & $0 \cdot 01$ & $0 \cdot 005$ \\
\hline
\end{tabular}

From Table 5 it can be seen that, with elevation angles of 20 degrees, the difference between the two mapping functions is 0.005 . Hence, with a zenith delay of $2.5 \mathrm{~m}$, the resultant range error, if the EGNOS model's mapping function were adopted instead of the Niell mapping function, at 20 degrees would be only $1.25 \mathrm{~cm}$. However, at an elevation angle of 5 degrees, the corresponding range error due to the adoption of the EGNOS model's mapping function would be $20 \mathrm{~cm}$, which is clearly more significant for navigation applications.

5. EFFECT OF EGNOS MODEL ERRORS ON POSITION QUALITY. Due to the variation in the satellite geometry with time and location, it is not possible to quantify directly the exact effect of any mis-modelling of the tropospheric delay on resultant position quality. Therefore for this study, GPS data were simulated for Lerwick and positions subsequently estimated over approximately a 2-week period (24 January 1999 to 6 February 1999). This 2-week period was selected since, from comparison with the GPS 'true' zenith total tropospheric delay estimates, the full range of errors obtained from the EGNOS model were present; that is, from 0 to $17 \cdot 8 \mathrm{~cm}$.

GPS pseudo-range data at a sampling interval of 60 seconds were simulated using a GPS data simulation package developed in-house at the IESSG. The broadcast ephemeris was used to provide the satellite positions and clock offsets, with no errors due to receiver clock offsets and ionospheric delay simulated, and the same ITRF94 coordinates for Lerwick as discussed in section 3.1. were used to generate the simulated data. Tropospheric delay was simulated using the 'true' 15 minute piecewise constant zenith total delay estimates obtained from the GPS carrier phase network solutions. Linear interpolation was used to obtain the zenith total delay at each 60 second epoch, which was then mapped to the appropriate receiver-to-satellite elevation angle using the Niell mapping function (Niell, 1996). Data were simulated with a 5 degree elevation angle cut-off. 
For each epoch, an independent stand-alone L1 pseudo-range position was estimated using least squares. With the exception of the tropospheric delay, compatible error models to those used in the data simulation were applied. Hence the broadcast ephemeris satellite coordinates and clock offsets were held fixed in the solution and the zenith total tropospheric delay was computed using the EGNOS model, then mapped to the appropriate receiver-to-satellite elevation angle using the EGNOS model's mapping function. Solutions were obtained for both 5 and 15 degree elevation angle cut-offs. The difference between the coordinates for Lerwick estimated at each epoch, and those used in the generation of the simulated GPS data, provided an indication of the error in the position estimate due solely to the use of the EGNOS tropospheric model and its mapping function.

5.1. Position Errors When Equally Weighting All Observations. In the first instance, the receiver position was estimated at each epoch with all observations to each satellite assigned equal weight. The position errors in the North (dN), East (dE) and height (dh) components obtained for both the 5 and 15 degree elevation angle cut-offs are shown in Figures 8 and 9 respectively. In addition, the zenith tropospheric delay error (dtrop) is also shown. Note that the gaps in the time series shown in Figures 8 and 9 are due to the lack of availability of GPS data for Lerwick for 1 February 1999. Epochs when the Position Dilution of Precision (PDOP) was greater than 10 were excluded from the analysis, since very large height and plan errors, of the order of several metres, arose due to weaknesses in the satellite constellation geometry. In practice at Lerwick for the 2-week period considered, no epochs were rejected due to high PDOP values for the 5 degree elevation angle cut-off case, and 198 epochs were rejected due to high PDOP values from a total of 16126 (i.e. about $1 \%$ ) for the 15 degree elevation angle cut-off case.

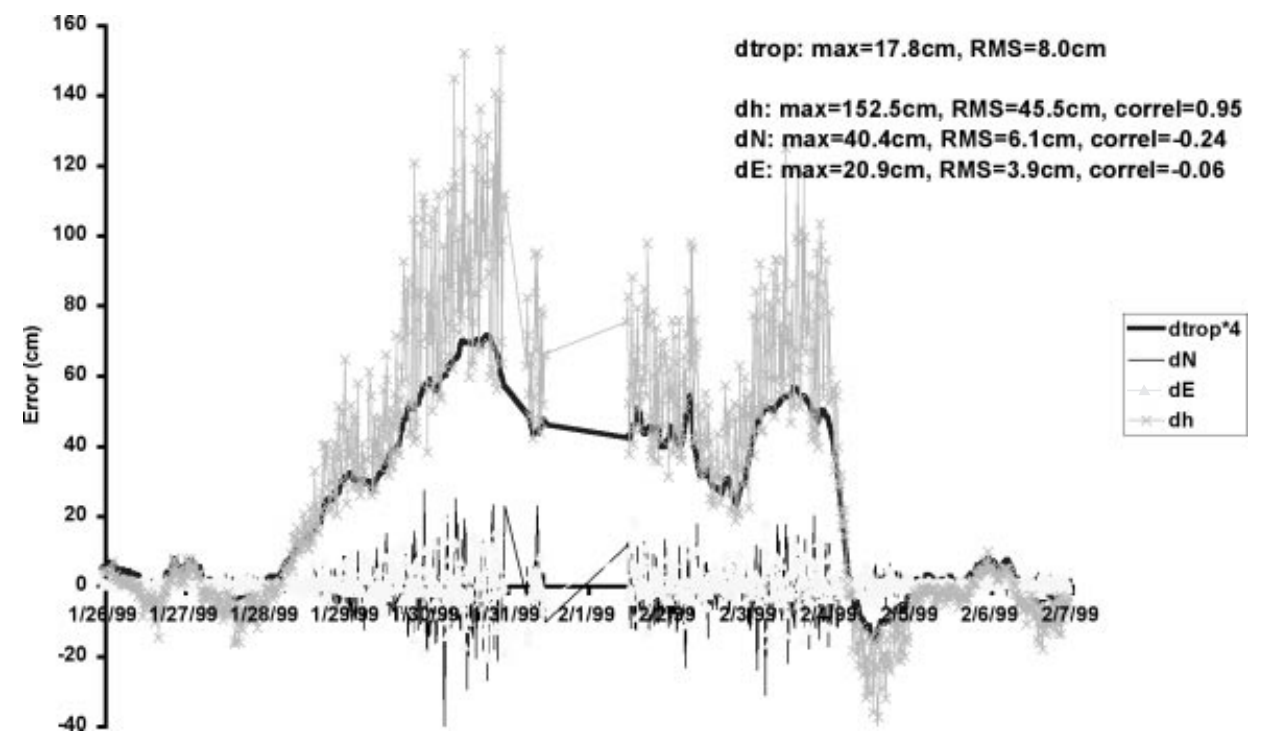

Figure 8. Effect of EGNOS model zenith tropospheric delay errors on position quality for Lerwick for a 5 degree elevation cut-off, all observations equally weighted. 


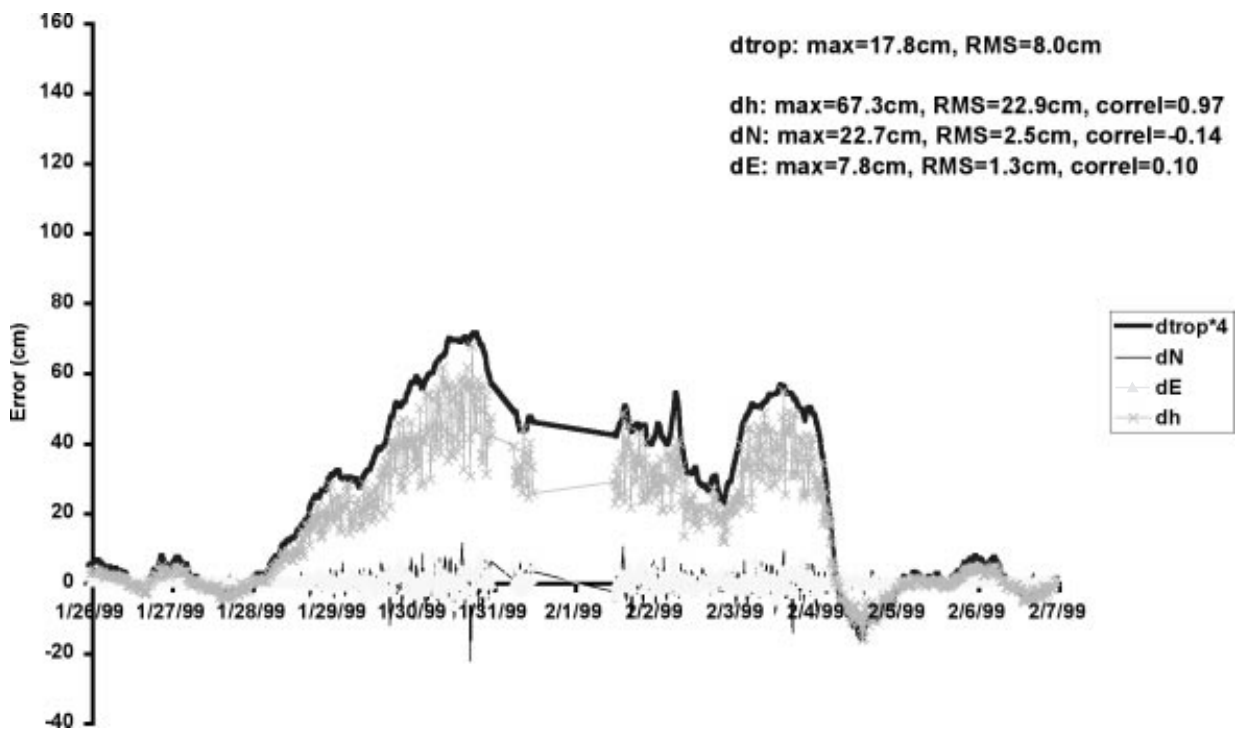

Figure 9. Effect of EGNOS model zenith tropospheric delay errors on position quality for Lerwick for a 15 degree elevation cut-off, all observations equally weighted.

Table 6. Effect of EGNOS model zenith tropospheric delay errors on position quality for Lerwick - all observations equally weighted.

\begin{tabular}{|c|c|c|c|c|c|c|}
\hline \multirow{2}{*}{$\begin{array}{l}\text { Elevation } \\
\text { Cut-off }\end{array}$} & \multicolumn{3}{|c|}{ Maximum Position Error $(\mathrm{cm})$} & \multicolumn{3}{|c|}{ RMS Position Error $(\mathrm{cm})$} \\
\hline & dh & $\mathrm{dN}$ & $\mathrm{dE}$ & $\mathrm{dh}$ & $\mathrm{dN}$ & $\mathrm{dE}$ \\
\hline 5 & $152 \cdot 5$ & $40 \cdot 4$ & $20 \cdot 9$ & $45 \cdot 5$ & 6.1 & 3.9 \\
\hline 15 & $67 \cdot 3$ & $22 \cdot 7$ & $7 \cdot 8$ & $22 \cdot 9$ & $2 \cdot 5$ & $1 \cdot 3$ \\
\hline
\end{tabular}

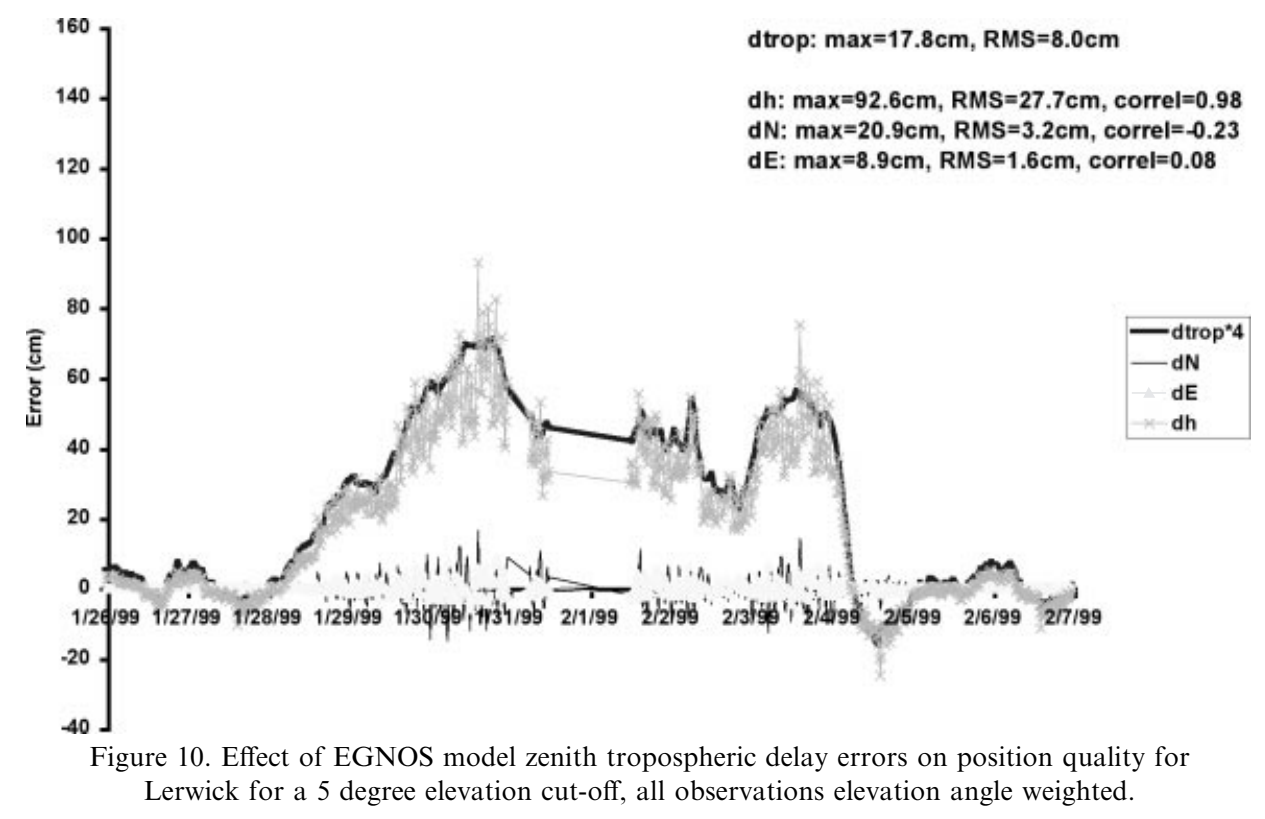


The maximum and RMS position errors for both the 5 and 15 degree elevation angle cut-off cases are shown in Table 6.

5.2. Position Errors When Using Elevation Angle Weighting. It has been shown that increasing the elevation angle cut-off reduces the effect of tropospheric model errors on position estimation, albeit with a worsening of the satellite geometry. However, in the tests detailed above, all observations were assigned equal weight. Now the maximum zenith tropospheric delay error due to the EGNOS model was $17.8 \mathrm{~cm}$, and at 5 degrees elevation this maps to a range error of about $180 \mathrm{~cm}$, which will propagate to the estimated position. To illustrate the effect of the inclusion of data from low elevation satellites with large tropospheric errors, the solutions were re-run for both the 5 and 15 degree elevation angle cut-off cases, but by weighting the observations according to the sine of the receiver-to-satellite elevation angle (hereafter termed 'elevation angle weighting'). This effectively downweights observations from lower elevation angles. The respective results are shown in Figures 10 and 11.

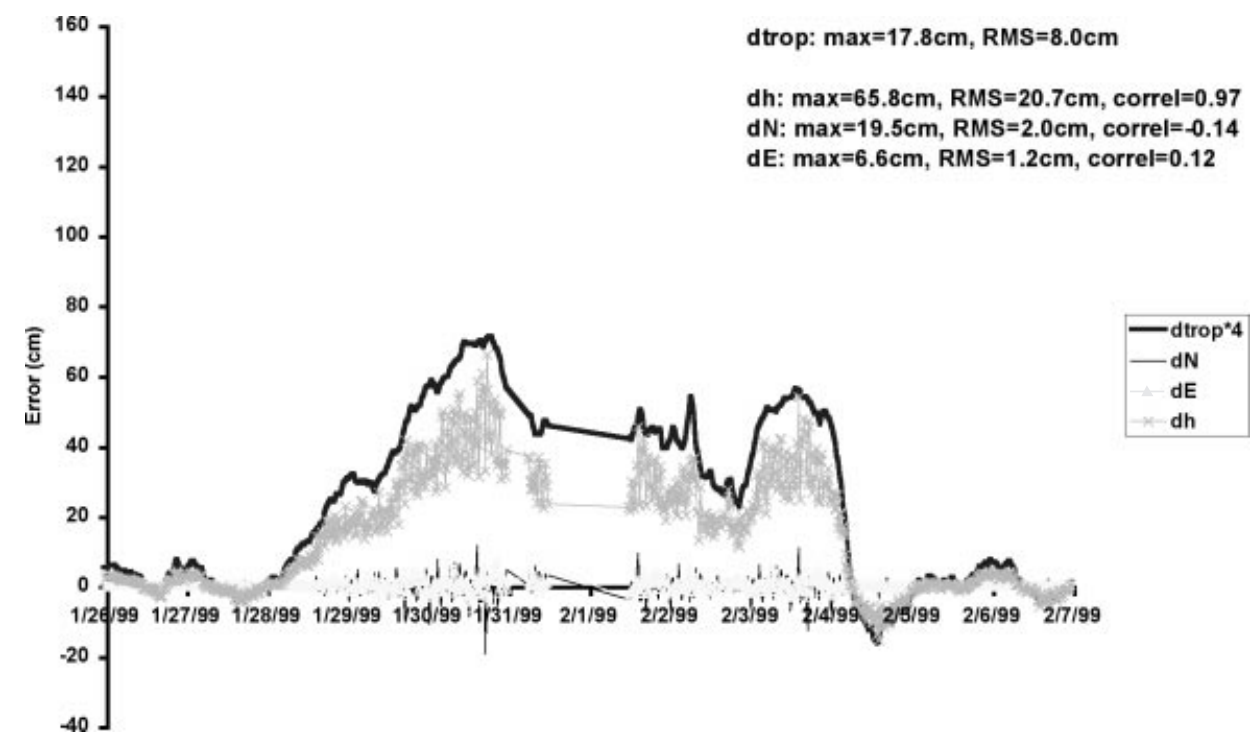

Figure 11. Effect of EGNOS model zenith tropospheric delay errors on position quality for Lerwick for a 15 degree elevation cut-off, all observations elevation angle weighted.

The maximum and RMS position errors for both the 5 and 15 degree elevation angle cut-off cases when the observations are elevation angle weighted are shown in Table 7.

Table 7. Effect of EGNOS model zenith tropospheric delay errors on position quality for Lerwick - all observations elevation angle weighted.

\begin{tabular}{cccccccc}
\hline \multirow{2}{*}{$\begin{array}{l}\text { Elevation } \\
\text { Cut-off }\end{array}$} & \multicolumn{3}{c}{ Maximum Position Error $(\mathrm{cm})$} & & \multicolumn{3}{c}{ RMS Position Error $(\mathrm{cm})$} \\
\cline { 2 - 3 } \cline { 7 - 8 } & $\mathrm{dh}$ & $\mathrm{dN}$ & $\mathrm{dE}$ & & $\mathrm{dh}$ & $\mathrm{dN}$ & $\mathrm{dE}$ \\
\hline 5 & $92 \cdot 6$ & $16 \cdot 3$ & $8 \cdot 9$ & & $27 \cdot 7$ & $3 \cdot 2$ & $1 \cdot 6$ \\
15 & $65 \cdot 8$ & $19 \cdot 5$ & $6 \cdot 6$ & & $20 \cdot 7$ & $2 \cdot 0$ & $1 \cdot 2$ \\
\hline
\end{tabular}


It can be seen from inspection of Tables 6 and 7 and Figures 8 to 11, that elevation angle weighting reduces the magnitude of both the maximum and RMS errors in all three coordinate components by about $50-60 \%$ for the 5 degree elevation angle cut-off case. For example, the maximum height error is reduced from $152.5 \mathrm{~cm}$ to $92.6 \mathrm{~cm}$. The effect on the position errors of elevation angle weighting for the 15 degree elevation angle cut-off is, as expected, less pronounced, with the resultant reduction in position error only about $5-15 \%$. For example, the maximum height error is reduced from $67.3 \mathrm{~cm}$ to $65.8 \mathrm{~cm}$. It can also be seen that, with the use of elevation angle weighting, the position errors obtained for the 5 and 15 degree elevation cutoffs are almost comparable, and adopting a solution with elevation angle weighting and a 5 degree elevation angle cut-off enables both good positioning quality and satellite geometry to be maintained.

It is clearly apparent from inspection of the trends shown in Figures 8 to 11, and from the correlation coefficients listed in the figures, that the height error is highly correlated with the zenith tropospheric delay error, although there is almost zero correlation between the zenith tropospheric delay error and the horizontal position errors. For clarity, these correlations are illustrated for the 5 degree elevation angle cut-off case with elevation angle weighting applied in Figures 12 and 13, with the coordinate component errors plotted against the error in the zenith tropospheric delay.

Figures 12 and 13 provide graphic illustrations of the degrees of correlation between the zenith tropospheric delay error and the position error. Since there is such a high correlation between the zenith tropospheric delay error and the height error, the gradient of the graph may be used to provide an approximate indication of how the zenith tropospheric delay error maps to a height error. Thus for the 5 degree elevation angle cut-off case with elevation angle weighting, this mapping factor is $3 \cdot 6$,

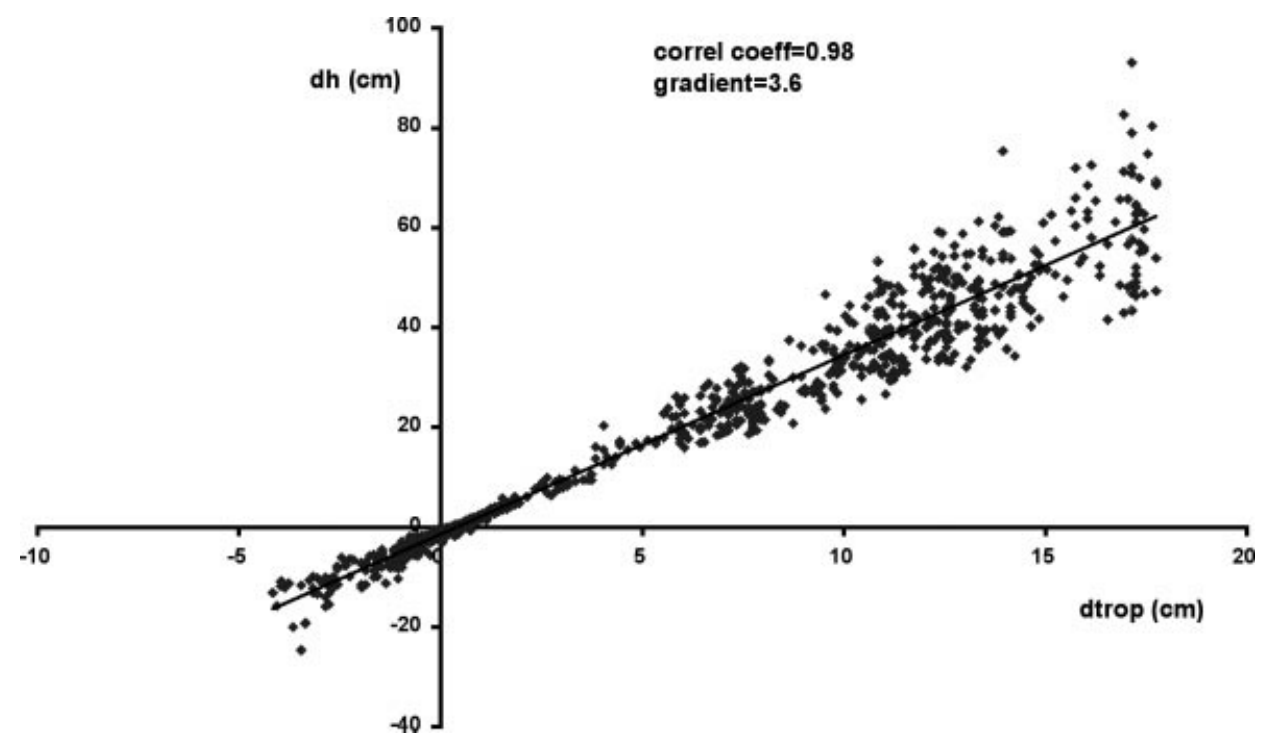

Figure 12. Correlation of height error and zenith tropospheric delay error for Lerwick for 5 degree elevation angle cut-off case with elevation angle weighting. 
whereas with no elevation angle weighting this factor is 5.9. For the 15 degree elevation angle cut-off cases, the respective factors are 2.6 and $2 \cdot 9$, when elevation angle weighting is and is not applied. These factors agree with the approximate 'rule of thumb' proposed by Brunner and Welsch (1993), whereby for a 15 degree elevation angle cut-off, a $1 \mathrm{~cm}$ zenith tropospheric delay model error can result in a height error of about $3 \mathrm{~cm}$.

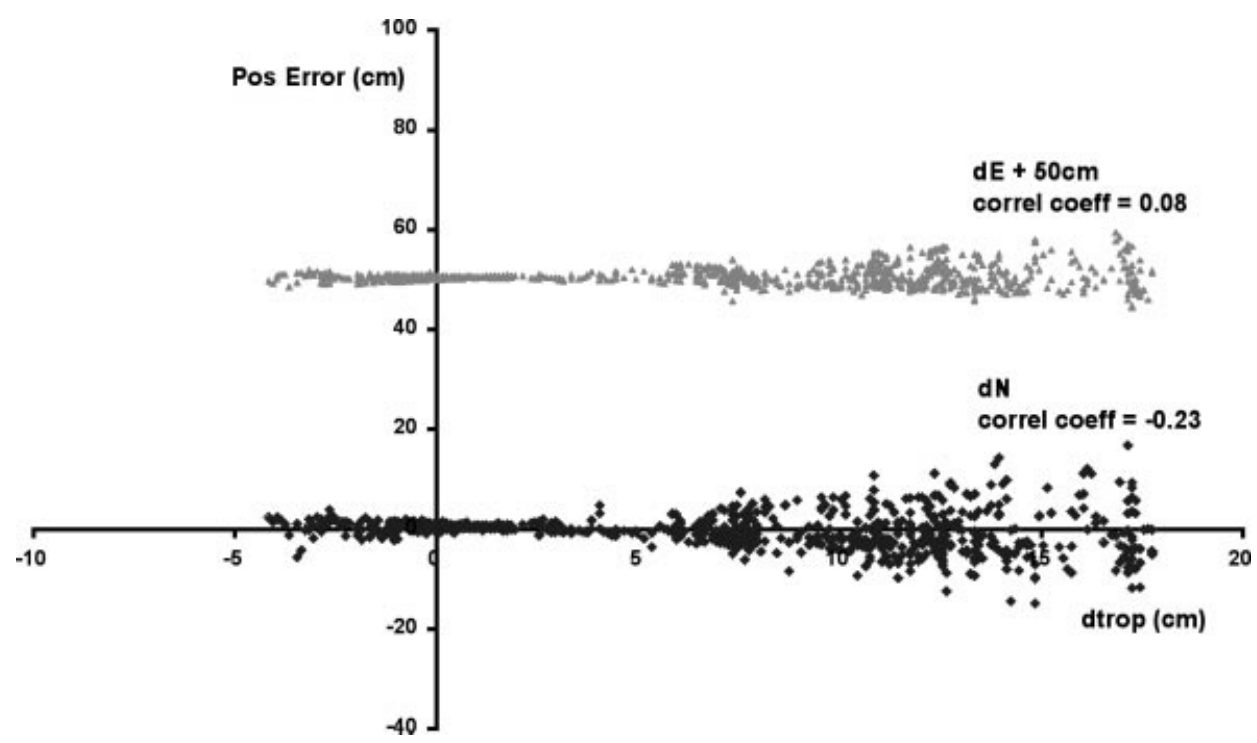

Figure 13. Correlation of plan errors and zenith tropospheric delay error for Lerwick for 5 degree elevation angle cut-off case with elevation angle weighting.

As illustrated in Figures 8-11 and 13, there is almost zero correlation between the zenith tropospheric delay error and the North and East component errors for both the 5 and 15 degree elevation cut-off test cases. This is almost certainly due to the azimuthal coverage of the satellite constellation, and the fact that no horizontal gradients in the tropospheric delay were simulated.

6. CONCLUSIONS. The EGNOS model was found to fit the average seasonal trends of GPS estimated 'true' zenith total tropospheric delays (correct to about $1 \mathrm{~cm}$ ) extremely well over a one-year period for five UK stations, which ranged in latitude from $50 \cdot 2^{\circ} \mathrm{N}$ to $60 \cdot 1^{\circ} \mathrm{N}$ and in height above mean sea level from 14 to $88 \mathrm{~m}$. For the five stations, the RMS errors ranged from 4.0 to $4.7 \mathrm{~cm}$. As expected, the EGNOS model failed to model tropospheric delay changes due to weather variations over short periods of hours and days, with maximum errors ranging from 13.2 to $17.8 \mathrm{~cm}$, whilst the proportion of errors exceeding $12.0 \mathrm{~cm}$, i.e. the maximum residual error stipulated in the EGNOS guidelines, ranged from 0.3 to $1 \cdot 1 \%$. However, the EGNOS model errors were found to be highly correlated spatially, with linear correlation coefficients of about 0.9 found for station pairs about $200 \mathrm{~km}$ apart, which decreased linearly to correlation coefficients of about 0.5 for station pairs about 
$1000 \mathrm{~km}$ apart. This strongly implies that tropospheric mitigation strategies using the EGNOS model could be improved by the augmentation of corrections to the EGNOS model broadcast from reference stations, at which high precision carrier phase GPS data could be collected and processed to monitor the tropospheric delay, located up to about $1000 \mathrm{~km}$ from the user.

The EGNOS model's mapping function was compared with the Niell mapping function and for a station (Lerwick) at latitude $60 \cdot 1^{\circ}$ North and height above mean sea level $82 \mathrm{~m}$, found to be nearly compatible. For example, for a 20 degrees elevation angle cut-off, the range error induced due to mapping function errors was only $2.5 \mathrm{~cm}$ and still only $20 \mathrm{~cm}$ for a 5 degree elevation angle cut-off, i.e. the minimum elevation angle for which the EGNOS mapping function is valid.

The resultant positioning errors due to EGNOS tropospheric model errors were assessed by the simulation of GPS data (for Lerwick over a 2-week period) to which 'true' total tropospheric delays were applied, and the station position estimated every epoch. For both 5 and 15 degree elevation angle cut-offs, the height error was found to be highly correlated $(>0.95)$ with the zenith delay error, whereas there was little correlation $(<0 \cdot 25)$ with the plan component errors. It was found that position errors were reduced by increasing the elevation angle cut-off, albeit with the need to reject some epoch solutions due to very poor satellite geometry. Also investigated was the effect of elevation angle weighting, which was found to be crucial for a 5 degree elevation angle cut-off, but almost negligible for a 15 degree elevation angle cut-off. If a 5 degree elevation angle cut-off was adopted with elevation angle weighting applied, the positioning errors were only slightly worse than those obtained for a 15 degree elevation angle cut-off, whilst the strength of the satellite geometry was maintained, in that no epochs were rejected. For example, over the 2 -week period, the zenith total tropospheric delay errors at Lerwick ranged from 0 to $17.8 \mathrm{~cm}$. For the 5 and 15 degree elevation angle cut-off cases with all observations equally weighted, the RMS height errors were $46 \mathrm{~cm}$ and $23 \mathrm{~cm}$ respectively, but when elevation angle weighting was applied, the respective RMS height errors were $28 \mathrm{~cm}$ and $21 \mathrm{~cm}$. Also, over this period, for the elevation-weighted 5 degree elevation angle cut-off case, on average the height errors were found to be approximately a factor of 3.6 greater than the zenith tropospheric delay error.

\section{ACKNOWLEDGEMENT}

The radiosonde, pressure and temperature data used were provided to the IESSG from the UK Meteorological Office, as part of the EC funded WAVEFRONT project (EC contract number ENV4-CT96-0301).

\section{REFERENCES}

Baker, T. F., Curtis, D. J. and Dodson, A. H. (1995). Ocean tide loading and GPS. GPS World, March 1995, pp. 54-59.

Bevis, M., Businger, T. A., Herring, T. A., Rocken, C., Anthes, R. A. and Ware, R. H. (1992). GPS meteorology: remote sensing of atmospheric water vapor using the Global Positioning System. Journal of Geophysical Research, Vol. 97, No D14, pp. 15,787-15,801.

Brunner, F. K. and Welsch, W. M. (1993). Effect of the troposphere on GPS measurements. GPS World, January 1993, pp. 42-51.

Collins, J. P. and Langley, R. B. (1997). A tropospheric delay model for the user of the Wide Area Augmentation System. Final Contract Report Prepared for Nav Canada, Department of Geodesy and 
Geomatics Engineering Technical Report No. 187, University of New Brunswick, Fredericton, N. B., Canada.

Collins, J. P. and Langley, R. B. (1998). The residual tropospheric propagation delay: how bad can it get? Proceedings of ION GPS 98 .

Dodson, A. H., Bingley, R. M., Penna, N. T. and Aquino, M. H. O. (1999a). A national network of continuously operating receivers for the UK. Geodesy Beyond 2000: The Challenges of the First Decade, International Association of Geodesy Symposia, Vol. 121, pp 367-372.

Dodson, A. H., Chen, W., Baker, H. C., Penna, N. T., Roberts, G. W., Westbrook, J. and Jeans, R. (1999b). Assessment of EGNOS tropospheric correction model. Proceedings of ION GPS99.

Dodson, A. H., Shardlow, P. J., Hubbard, L. C. M., Elgered, G. and Jarlemark, P. O. J. (1996). Wet tropospheric effects on precise relative GPS height determination. Journal of Geodesy, Vol. 70, pp. $188-202$.

IGS (2000). http://igscb.jpl.nasa.gov/components/prods.html.

Le Provost, C., Genco, M. L., Lyard, F., Vincent, P. and Canceil, P. (1994). Spectroscopy of the world ocean tides from a finite element hydrodynamic model. Journal of Geophysical Research, Vol. 99, No C12, pp. 24,777-24,797.

McCarthy, D. D. (ed.) (1992). IERS standards (1992). IERS Technical Note 13, Observatoire de Paris, July 1992.

McCarthy, D. D. (ed.) (1996). IERS conventions (1996). IERS Technical Note 21, Observatoire de Paris, July 1996.

Niell, A. E. (1996). Global mapping functions for the mapping of the atmospheric delay at radio wavelengths. Journal of Geophysical Research, Vol. 101, No B2, pp. 3,227-3,246.

RTCA (1999). Minimum operational performance standards for Global Positioning System / Wide Area Augmentation System airborne equipment. RTCA DO-229B, Issued 10 June 1999.

Rothacher, M. and Mader, G. (1996). Combination of antenna phase center offsets and variations. Antenna Calibration Set, 30 June 1996, File IGS-01.PCV, IGS Central Bureau Information System.

Saastamoinen, J. (1972). Atmospheric correction for the troposphere and stratosphere in radio ranging of satellites. The use of artificial satellites for geodesy. Geophysical Monograph Series, AGU, Washington DC, Vol. 15, pp. 247-251. 